The Design Journal: An International Journal for All Aspects of Design, 2013, Volume 16, Issue 4, pp 408-430

\title{
Critical Reflections on Designing Product Service Systems
}

\begin{abstract}
In response to unsustainability and the prospects of resource scarcity, lifestyles dominated by resource throughput are being challenged. This paper focuses on a design experiment that sought to introduce alternative resource consumption pathways in the form of product service systems (PSS) to satisfy household demand and reduce consumer durable household waste. In contrast to many other PSS examples this project did not begin with sustainability benefits, rather the preferences of supply and demand actors and the bounded geographical locations represented by three UK housing developments. The paper addresses the process through which the concept PSS were designed, selected and evaluated, alongside the practical and commercial parameters of the project. It proposes the need for a shift to further emphasise the importance of the design imperative in creating different PSS outcomes that reorganise relationships between people, resources and the environment.
\end{abstract}

\section{Keywords}

Product Service Systems (PSS), Design Process, Evaluation 


\section{A Rationale for PSS}

The current consumption of natural resources by industrialised nations is not sustainable. Sustainability involves changing individual beliefs, expectations, values and behaviours, changing governance policy and directions and changing the design of society and its structures. Design for sustainability has a big challenge: a ninety percent gain in energy and material efficiencies over the next thirty years (Schmidt-Bleek, 2000). Bottom-up and topdown design and policy interventions are needed at all levels. In creating a liveable world for future generations a shift in emphasis is required in design, moving from an operational perspective of product and process to include a more strategic position concerned with ways of delivering an effective mix of design outputs for society (for example Product Service, Systems - PSS) and the policies and political processes that link to this transition. Design in the context of sustainability needs to concern itself with enlarging the imagination of what sustainability can mean beyond eco-efficiency.

The research reflected here responds to this agenda of delivering an effective mix of design outputs for society. It was funded by the Department for Environment, Food and Rural Affairs (Defra) and was undertaken in partnership with a large UK house builder. This paper addresses design at the levels of organisational output and individual consumer choice in the context of three UK housing developments in three different regions. The project presented a useful opportunity for the house builder to explore what might constitute a new offer to future and existing householders in the form of a range of more resource efficient domestic services. Although the research comprised many parts, the focus of this paper is to describe the design process used to develop exploratory PSS for the three urban housing developments and to present some of the practical issues drawn out from a process geared to producing 'services' rather than products. We also reflect on the evaluation of the PSS in terms of both the house-builder's and householders' priorities and preferences for home services when gauged against traditional measures such as cost, quality and convenience.

Before we engage with the specific design process of the PSS, firstly it is necessary to establish what is meant by PSS. Traditionally sustainable design has focused on how various social, environmental and economic performances can be attained through product design, i.e. the design of material artifacts. However, the potential of systems of products and services which include both non human (e.g. material artifacts) and human actors (e.g. users) to provide services which meet individual demands as well as to attain public goods such as sustainability is now the subject of a growing literature (cf Roy, 2000; Bartolomeo et al., 2003; Williams, 2007; Mont and Emtairah, 2008; Gottberg et al., 2010). The ideas underpinning PSS are quasi evolutionary: the emergence of services in manufacturers' product portfolios sectors are thought to provide opportunities to purposively develop systems of products and services which satisfy demand using far fewer resources.

Many manufacturing firms now use the good(s) they produce as platforms for service innovations (cf. Howells, 2002; Baines et al., 2007). A number of manufacturers have developed service innovations that complement their goods (e.g. extended warrantees, maintenance contracts), while others have used the goods they produce to develop performance/ result orientated service innovations that are potential substitutes for these. Notable examples include document handling services that are potential substitutes for photocopiers and power services that are potential substitutes for gas turbines. And in such instances, it is suggested that service innovations may now be more important to manufacturers and their customers than the goods they produce as performance is defined and rewarded in terms of results achieved (Beherendt et al., 2003).

Various definitions of service innovations have been developed from case study research and include: eco-efficient producer services (Zaring et al., 2001), eco-efficient services (Hockerts, 1999; Meijkamp, 2000; Brezet et al., 2001), eco-services (Beherendt et al., 2003) and product service systems (Goedkoop et al., 1999; Mont, 2004; Tischner, 2002). The latter term product service system (PSS) is used extensively in recent literature: 'A system of 
products, services, networks or actors and supporting infrastructure that is developed to be competitive, satisfy customers and be more environmentally sound than traditional business models', (Mont, 2004). PSS design is thought to principally be concerned with: 1) a focus on the functionality or satisfaction that the user wants to realize; and 2) the provision of functionality with a Greenfield mindset (Tukker \& Tischner, 2006).

To further support PSS design a number of PSS types have been elaborated. These include product, use and result orientated PSS, which in theory at least, should improve resource productivity and help mitigate the environmental, social and economic impacts associated with resource extraction, synthesis, use and disposal (Hockerts, 1999; Roy, 2000; Cook et al., 2006). These include product orientated PSS (e.g. extended warrantees) and use orientated PSS, e.g. leasing, sharing and polling products. Performance orientated services such as those focused on above are defined as result orientated PSS: 'Result orientated PSS: ownership rights of the material artifact (good) required for service delivery are retained by the service provider (who may or may not have manufactured it); the customer purchases an outcome/ result of service provision, which is specified in terms of performance not the use of a good over a period of time. For example, instead of renting a washing machine, households use a laundry service to clean clothes and linen', (Cook et al. 2006).

Potential gains in resource productivity through adopting result orientated PSS are thought to arise in a number of ways. First, if the ownership rights pertaining to product elements of PSS are held by the PSS provider then profit seeking PSS providers gain an interest in avoiding the costs associated with maintenance, repair and disposal associated with product elements and in response develop or select more durable and efficient ones. Second, if the ownership rights pertaining to product elements of PSS are retained by providers and PSS used to substitute traditional consumption methods, then a smaller stock of products may be needed to satisfy demand. Third, producers may also use their competencies to select appropriate products to support PSS and ensure that these are used correctly (Cook et al. 2006). Such predicted behaviors led to suggestions that PSS could achieve significant improvements in resource productivity, e.g. factor ten plus (cf. Weizsacker et al., 1997; White et al., 1999).

Various environmental assessments were completed to test these initial claims. These show among other things that PSS performance is indeed, differentiated by type and that result orientated PSS hold significant potential to foster large improvements in resource productivity, although the scale of these remains unknown (Tukker and Tischner, 2006). They also suggest that services are not inherently more resource efficient than traditional production and consumption methods based on exchange of products at point of sale. And thus that simply encouraging a shift from products to services may not put society on a sustainable development pathway. This adds support to the view that improvements in among other things, resource productivity are unlikely to be gained merely from the unfettered emergence of service innovations and that among other things, PSS may need to be purposively designed in specific contexts to deliberately realize such social benefits (Mont, and Lindhqvist, 2003; Cook et al., 2006). This paper helps to address this gap in knowledge through generating practical knowledge of PSS design and evaluation. It focuses on the purposive design of result orientated PSS to achieve waste prevention in new UK housing developments where in depth insights on household preferences for a small number of deliberately designed, result orientated PSS were sought and where the metric of waste prevention was set by the funder, Defra. However, the paper also takes two further limits to PSS research into account.

First, that the sustainability benefits of PSS have formed the focus of case study research and that PSS designed to attain performances such as improved resource productivity and waste prevention may not be commercially interesting and therefore by extension, have little chance of being taken up in markets and their wider sustainability benefits realized (Mont and Tukker, 2006). Therefore the potential for this particular PSS design process to achieve 
sustainability benefits is for its practical relevance to be determined through reflecting the preferences of the major actors involved; namely: a large speculative house builder, its facilities management service suppliers and the householders. Second that the PSS research field is underpinned by a number of case studies and that knowledge has not been systematically accumulated inhibiting coalescence and theory building in the field (Tukker and Tischner, 2006). To address this an evaluation approach was also developed in the project to enable the preferences of actors engaged in PSS design to be identified and systematically reviewed. The effectiveness of this approach in PSS design is considered in this paper and it is hoped that it may enable and support systematic knowledge accumulation in the PSS field.

\section{Designing result-oriented PSS}

A design process for exploring result oriented PSS in this practical and specific context of three UK housing developments is detailed in Figure 1. This comprises three key stages that reflect the design and evaluation of PSS concepts. The first stage involves understanding the ecological, organizational and user contexts of the PSS - the context - and builds up a picture of the desired PSS performance preferences and priorities from the perspective of both supply and demand actors. The second stage generates conceptual PSS concepts in response to the initial research and in discussion with the house builder and its facilities management services these concepts are further developed. The third stage evaluates the chosen PSS concepts from both supply and demand perspectives; both quantitative and qualitative methods were used, supported by the performance criteria generated in stage one. The dynamic of this process broadly reflects existing product design process methodology in that the journey iteratively weaves between defining and redefining the problem space while formulating a solution space in response to an evolving, deeper understanding of both problem and context (Dorst and Cross, 2001, Pahl et al, 2007). However, unlike well-documented product design methodology, the focus was not a product but rather systems of products and people, non-ownership, service agreements and challenges concerning the shift from normalized product ownership transactions to financial transactions concerning labour and expected outcomes. In simple terms this process needed to respond to the additional complexity of understanding the practical logistics of a PSS alongside interpreting the environmental requirements of waste reduction required by the project funder. The aim of the research was not to produce a tightly defined and specified outcome but rather to produce recognizable deliverables that people could engage with and discuss and thus provide clearer insights on the viability of PSS, as defined here, and the limits and opportunities for such concepts to evolve in domestic contexts.

Figure 1 A PSS design process (place about here)

\section{$2.1 \quad$ Understanding Context}

The first stage of the design process involved collecting data about the context of the potential PSS from both supply and demand perspectives. Supply side participants were drawn from various functions of the house builder and their supply chain and were targeted for their engagement with the development and sale of after sales products to new householders; their experience of service delivery; their involvement in sales and marketing; their technical knowledge of environmental issues for example; and their knowledge of trends in household demand. Representatives from facilities management, supply chain management, customer service, environmental management, marketing and a housing association were included in this early engagement through semi-structured interviews and a focus group. Supply-side discussions were transcribed and clusters of codes revealed performance criteria for the development of the PSS: namely; external factors: regulatory framework and market conditions; and internal factors: existing product portfolio, corporate strategy and competence and organizational structure. Demand side householders from one of the housing developments engaged in six semi-structured interviews and a focus group. Interviewees were asked to reflect on the household tasks and activities undertaken in a 
typical day and the range of products used to support these activities and the way in which the activities were undertaken. These discussions created a rich picture of daily household behavior with a number of activities identified as amenable to PSS delivery: Admin/working from home; clothing and linen care; house cleaning; home improvement; food shopping, preparation and storage; garden maintenance; and leisure/home entertainment. In considering adopting result oriented PSS, householders raised specific demand-side performance criteria. Issues of cost and price were considered important criteria where the perception was that services are usually more costly than product ownership.

During this early stage it was also critical to consider the practical and environmental context of developing the potential PSS concepts. A map of supply side interconnections was generated through interviews with representatives of sales, after-sales, marketing and environmental functions of the house builder. Further environmental data was collated from external sources such as Government priority impact areas and existing and potential environmental legislation. This was used to generate areas of focus for the organization in response to external conditions, particularly in response to the funded research project's mandate to understand the relationship between PSS and an overall reduction in waste in households.

\section{$2.2 \quad$ Developing PSS Concepts}

A workshop was held with the house builder and its facilities management business. The aim was to develop a number of PSS that could be practically implemented across the three housing developments. Different types of PSS were presented to supply-side actors to provide a consensual understanding of the scope of PSS. These included a product oriented focus (maintenance and repair); a use focus (e.g. renting and pooling of products); and a result focus where the supplier provides the desired outcomes previously satisfied through self service using individually owned products. Based on the earlier context building research the potential landscape of results oriented PSS was presented, specifically a new concept of the home lifecycle as shown in Figure 2. The generation of the household 'life-cycle' model provided an initial means to explore PSS concepts focused on product, use and result orientation. This model reflected the conceptual idea to deliver reduced environmental impacts across the whole house-life without the transfer of impacts throughout the lifespan and across the ownership of the home. This ideology is similar to that of a product lifecycle approach. However, the house builder felt this was too radical a leap and instead wanted to focus efforts on immediately operational PSS within their current frame of business practice.

Figure 2 Home lifecycle (place about here)

Building on the linkages between householders, houses and their whole lifespan, a few PSS concepts had been generated prior to the workshop. These aimed to reduce the environmental impact, specifically waste prevention by households, across a range of domestic activities such as the ownership of consumer durables, the purchase and cooking of food, domestic waste flows, clothes washing, gardening, home improvement, and house resale and subsequent ownership. The house builder was most interested in understanding the potential of PSS in the specification, sale and use phases as these are the home 'life times' that aligned to their current remit and were therefore the most familiar to them. The potential opportunities for more effective environmental improvements from a result focused PSS compared to product or use focused strategies (Tukker and Tischner, 2006) were presented in this operational context. The environmental benefits were sketched out as follows: a smaller stock of home owned products (a reduction in overall Waste Electronic and Electrical Equipment, WEEE); a higher use yield per product before natural obsolescence (where product lifespan is increased through repair and maintenance by service provider); and the investment in more durable goods by the service provider (to reduce labour and material costs for repair and maintenance during a product's use stage). Financial benefits and revenue flows were explored in the context of the house-builder's current service model used by their facilities management business. The need to meet householder needs 
regardless of product ownership was discussed. The house-builder was reluctant to consider the leasing of products, primarily due to costs where recent research illustrates that leasing is no cheaper than buying, but additionally reasons reflected sector priorities and preferences for direct sales.

Through discussions of such concepts the workshop participants began to formulate potential ideas for their own PSS; these focused on processes already visible and operational in the facilities management side of the organization and which provided a certain confidence to the participants that they could feasibly deliver such solutions and thus share these with the three regional household focus groups. The selected PSS concepts involved different types of services that could be delivered to the household on a one-off or continuous basis. The house-builder chose result orientated PSS that they believed to be practical and marketable options in preference to more blue sky concepts such as the home life-cycle service agreements that ventured too far from their existing infrastructures and processes used by their sales team and their facilities management business. Importantly, given the housebuilder was to be the 'face' of the PSS, they were most concerned with the nature of the service delivery and the ability to manage these processes onsite and to protect their brand, particularly the coherency, trust and quality of PSS outputs over time

\subsubsection{Selected PSS}

Based on the feedback from the workshop, the PSS concepts were further developed with the house-builder to construct a menu of four PSS concepts to present to the householder focus groups and interviewees for evaluation. These were designed to satisfy demand for home improvement, garden maintenance, laundry (clothing and linen) and house cleaning. Waste reduction in the system was addressed through a proposed decrease in ownership of domestic products in the individual households. Instead, householders' needs would be met though service provision where product utility is shared and labour is bought in. Figure 3 provides an illustrative example of two of the PSS concepts for house maintenance and laundry services. In the house maintenance PSS the householder buys shelves but realizes she does not have the tools to construct and install them. She phones the local service provider and organizes a time to drop off her key at the local centre and for a specialist trades person to access her home while she is at work and to carry out the task of building and installing the shelving. This was a one-off job paid for by the householder. In the second PSS example the service responds to an on-going need for clean clothes. The households do not own a washing machine but access a weekly laundry service via a secure bin drop off outside the house. The householders place their dirty clothes in the bin, which they then lock. The laundry service collects the contents of the bin and at the same time replaces its contents with the previously collected clothing that is now clean. The bin is locked again ready for the householders to collect their clean washing.

Figure 3 Home improvement and laundry PSS (place about here)

These examples show that the PSS could be ordered on demand and/ or via subscription of regularly recurring PSS over a given period of time. Approximate costs associated with the concept PSS were developed using the house builder's accounting model. A process for PSS management and delivery was enumerated and costs associated with each aspect of this identified. The house builder's facilities management division would manage the menu of PSS and regional service suppliers from the house builder's supply chain would undertake delivery on new housing developments. The accounting model used cost plus pricing and profit margins of 3-4\% were sought. Indicative prices for each of the PSS were identified to enable households to assess these against other criteria at the three subsequent householder workshops. An overview of the environmental impact reduction and the demand and feasibility of each PSS is described in Table 1.

PSS Concept Waste Prevention Potential

Customer Demand \& Feasibility of Supply 
Home Improvement own specialist DIY tools

- Electric tools make up 3\% of WEEE; circuit boards potentially contain hazardous substances; cordless tools contain batteries - Eventual end-of-life waste resides with service firms $=$ potential for policy intervention

Garden Maintenance

Laundry (Clothing and Linen)

House Cleaning
- Individual household do not need to own specialist garden tools - Lawn-mowers + other electrical equipment make up $3 \%$ of WEEE; cordless tools contain batteries

- Eventual end-of-life waste resides with service firms $=$ potential for policy intervention

-Washing machines \& tumble dryers - Large household appliances make up $43 \%$ of WEEE; circuit boards may contain hazardous substances - Eventual end-of-life waste resides with service firms $=$ potential for specific sector policy intervention

- Main products are vacuum cleaners, detergents, cloths and similar.

- Vacuum cleaners + other electrical equipment make up $3 \%$ of WEEE; circuit boards may contain hazardous substances

- Eventual end-of-life waste resides with service firms $=$ potential for policy intervention
New house buyers seek professional skills re adapting / customising their home.

Very feasible: it requires systems, equipment and skills similar to existing customer services;

Service is already familiar to some residents; new house move is disruptive \& therefore this provides replacement, trustworthy service.

Very feasible:

Easy skills to locate

DIY laundry perceived to be convenient and cheap and provide flexibility. Laundry service deemed costly - used infrequently for large loads.

Feasible: Pilot concierge service providing a dry-cleaning service

High demand service \& for new householders this provides trustworthy option.

Very feasible: Sourcing cleaners is an existing housebuilder concierge service

\section{Table 1 The Characteristics of the Concept PSS}

All the PSS concepts were familiar services; none presented a radical departure from the norm other than the concept of non-ownership of domestic products. The key reason for the use of such familiar services was the house builder's desire to present PSS concepts that they felt comfortable with, that they felt their house buyers would understand and that they considered would be viable to facilitate in reality. The assumptions made in these example narratives are that the PSS are practical and doable in the short-term and are able to demonstrate a reduction in waste. However the environmental and waste reduction benefits of an increased uptake of such services depends on a number of things: the nature of the use patterns of the professional suppliers compared to households owning material artefacts for self-provision of the same result; a demand-side non-ownership of product - in other words house owners forgo owning their own equipment to utilise a PSS; and the key attributes of costs and reliability of PSS are accepted by householders who continue to utilise these services in preference to purchasing their own products.

\subsection{Evaluating the PSS Concepts}

Since neither a definition of result orientated PSS nor a relevant counterfactual are systematically built upon in the PSS literature, definitions were generated in the project from existing ones, to enable a robust approach to PSS design and assessment. Similar to Heiskanen and Jalas (2003) we suggest that the origin of labour input and environmental performance enable result orientated PSS and current household consumption practices to 
be differentiated. Thus following Gershuny and Miles (1983) traditional household consumption is defined as self service, which comprises household labour and material goods: Self Service (SS) involving household goods that are used by householders to produce services for their household. Self service involves the combination of labour (informal and non-monetised) and a material item - a household good, which is owned by the household. Self service is also supported by infrastructure and intermediary services, e.g. consumables in use and labour and materials for repair. As an alternative to self service, households may choose to consume a household service provided on markets via for example, a social enterprise or a public or private organization; in this case, a house builder. In a household service, tangible artefacts, (defined as capital goods, which are owned by service providers and used to support service delivery) are combined with formal, monetized labour to produce the service. In this design experiment, result orientated PSS are differentiated from household services as these specifically aim to provide superior environmental performance than self service.

The four selected PSS were required to integrate within the house-builder's existing portfolio of after sales products, which included curtains, kitchen appliances, electronic goods and carpeting. The new housing developments at which the PSS were presented were located in the South East and North West of England and comprised 300, and 700 private dwellings respectively. They were chosen by the house builder as they were of a sufficient scale to provide the possibility of on site service centres and a geographical density of demand to provide the possibility of commercially viable PSS, thus minimizing environmental disbenefits of PSS arising from the environmental impacts of transportation (van den Hoed, 1997). The PSS narratives were introduced to householders one by one, using storyboards detailing the journey of each service, as illustrated in Figure 3. The PSS storyboards provided a visual representation of the PSS process, including ordering and delivery, with details of key agents, activities involved and, importantly, ballpark costs based on the facilities management's cost model. The narratives gave accounts of such processes from a range of household perspectives with stories of PSS consumption constructed around families, married couples and single people. As well as explaining the 'make-up' of each PSS and describing how people would interact with them, the research team also undertook an evaluative process organized through a focus group discussion of each of the concepts and a detailed questionnaire that explored the different criteria and choices for each PSS scenario. This evaluation was based on the multi criteria collected from supply and demand actors in the early research phase of the project. In-depth interviews with householders were also undertaken.

\subsubsection{Evaluating Producer and Household Preferences for the PSS Concepts}

The PSS discourse emphasises the need for designers to develop PSS that respond to user needs and preferences. Similarly, in order to be successful PSS must be commercially viable too. The bespoke assessment method is based on the analytical hierarchy process (AHP) that forms part of the family of multi-criteria assessment (MCA) methods (Saaty, 1980). AHP is used in projects such as this design experiment, where few data are available (Taha, 2003), i.e. on PSS performances on new UK housing developments. In this project, producer (house-builder and facilities management service providers) and householder preferences were identified and incorporated within a MCA method developed within the project to enable these actors to evaluate each PSS. The results of a literature review, which drew upon services marketing and management, service innovation and PSS literatures were combined with the results of primary data collected on priorities and preferences, to develop a set of design criteria to inform the multi-criteria evaluation model. As part of the evaluation process householders completed a questionnaire, each answering questions which enabled them to assess their preferences for the PSS concepts or current self service to satisfy aspects of their household demand.

The quantitative data showed demand side drivers for the voluntary uptake of the PSS to be: minimising financial cost through not buying the product required for self service; quality of 
the outcome where householders perceive they have a lack of competence to complete a self service outcome to a satisfactory level and seek expertise through adopting PSS (e.g. home improvement); minimising time where householders are willing to substitute disposable income for spare time; and quality of process where householders do not enjoy completing self service and would prefer the PSS option. The AHP data also illustrated the barriers to demand side take up of PSS that included: minimising financial cost where the relative costs of PSS are deemed too high in comparison to self service options or householders already own the product required to complete self service; quality of outcome where householders have a specific competence to complete self service and achieve desirable outcomes; quality of process where householders enjoy self service (e.g. gardening); lack of convenience of PSS where householders perceived self service would avoid the inflexibility, or lack of availability, of PSS; and a general lack of interest in minimising environmental criteria where PSS is not stimulated if householders do not demand improved environmental performance or understand the environmental benefits possible through PSS uptake. In summary the AHP data showed that there was relatively more demand for self service with sixty per cent of respondents preferring this to the PSS option. However this does mean that forty per cent of respondents showed a preference for PSS indicating future potential for such services. In particular demand was greatest for home improvement and garden maintenance PSS where additional skills or tools were required and where costs were perceived to reasonably match the need.

The qualitative interview data supported the results of the AHP. Householders stated that they were more likely to use garden maintenance and home improvement services. The perception was that garden maintenance would be more affordable than say a laundry PSS due to its periodic, seasonal requirement; that it would not offer the same security risks given service providers would have no need to enter the home (something that put people off in terms of the house cleaning service); and that it was perceived as a low risk option compared to a more critical requirement of having access to clean clothes. Perhaps not surprisingly there was relatively less interest in the laundry PSS where respondents felt vulnerable in trusting that a service could process a family's washing requirements in a reasonable timescale and at a competitive price; for example there were concerns about the service turnaround on garments that are frequently laundered such as underwear and school sports kit. The demand for home improvement PSS was largely from respondents who perceived they lacked the requisite skills or tools to achieve good quality outcomes. The cost of home improvement PSS was less of an issue compared to other PSS offers as respondents felt they would receive a high quality outcome in contrast to attempting the job themselves.

Two workshops were held with producers: one with representatives of the house-builder; the other with representatives from its facilities management business. Here the performance of the PSS was compared with business as usual (BAU): for the house-builder, they continue to supply after sales products; for the facilities management providers, they continue to supply services to commercial clients rather than households. Responses were inputted into the AHP model which was informed from the primary data of supply side criteria found to affect producer preferences for PSS such as profit maximisation, the ability to meet legislation and the ability to maximise customer satisfaction. The results from the supply side model suggest that representatives of the house builder had a positive view of PSS. Most respondents selected PSS because it was perceived to have potential to perform better than BAU in terms of the maximising customer satisfaction. Where BAU was selected, it was where this performed better against either maximising customer satisfaction or profit maximisation criterion. However, in contrast there was a clear reluctance among facilities management service providers to produce PSS. Most would not produce PSS because they simply did not align with their current core business where there was no perceived demand for PSS scenarios.

\subsubsection{Waste Prevention and Environmental Assessment}


Waste prevention and environmental assessments were completed to gauge the potential of PSS compared to current production and consumption, described here as self service. Functional equivalence was established between the four PSS concepts and corresponding self service to ensure that the alternatives assessed were comparable, even if the alternatives represent different means of fulfilling the same function. The stock of products used to satisfy demand which when disposed of are classified as WEEE, formed the focus of the assessment: electric drills, lawn mowers, vacuum cleaners and washing machines. The waste prevention potential was based on a comparison between two prospective situations: the quantity of WEEE generated by households undertaking self service; and the quantity of WEEE generated from consumption of the experimental PSS which displaces a proportion of self service. The waste prevention assessment showed that the PSS held potential to prevent significant quantities of WEEE under certain conditions. While the PSS concepts held potential to prevent WEEE even when consumed as a complement to self service, their performance was highly sensitive to changes in household behaviours (Gottberg et al., 2010). For example, if a household chooses to consume a laundry service as a complement to self service, the size of washing machine used for self service and the length of time the household retains this has significant impact on waste prevention performance. From the supply side there was a perceived barrier to PSS uptake because of the absence of environmental regulations. It was felt that PSS supply would not be stimulated unless appropriate environmental regulations were in place. There was a willingness demonstrated among service providers to comply with environmental regulations for PSS (e.g. mandatory eco-labelling for services)

\section{Discussion and Conclusions}

In this design project, context really mattered as it was constrained by the commercial interests and the institutional situated knowledge of the house-builder. This is an important contribution to PSS knowledge where there will be limits to the ongoing accumulation of context free and generalisable knowledge. The house-builder's rules of engagement for new projects were implicitly applied here: it was critical that this project, representing a virtually untested idea, should connect to the house-builder's core competences and structures to create a 'low-risk' investment. The new housing development context embodied a lower risk approach for PSS as they offered geographical densities where the preferences of the supplier could be addressed in terms of co-ordinated service provision and economies of scale. In developing PSS concepts it became clear that the task of giving form to the little understood construct of PSS alongside commercial interests, environmental benefits and supply and demand preferences, resulted in a rather closely defined design boundary; rather than a limit transcending activity, the potential of this experiment became one of defining and articulating those limits for real-world service provision.

The experiment focused on the early phase of a design process in generating potential PSS concepts for user evaluation. Early design processes are purposely open to allow expansive, lateral creative development to occur. However, in this instance, the complexity involved in defining results oriented PSS, particularly for the service provider and their known market of home owners, channeled the development of the PSS concepts away from different, more abstract outcomes and towards the familiar territory of 'man with a van' service provision. The nature of the PSS presented to the householder focus groups was determined by practical and short term delivery concerns of the supplier in that the result oriented PSS concepts were realistic and 'doable' through the existing infrastructures and finance models of the house-builder's businesses such as their current contract cleaning and maintenance programmes.

The more radical concepts of service delivery presented in the early stages of the design process were considered too far removed from the day-to-day practice of the house-builder and thus difficult to understand and to market to their customer base. From a design perspective this was frustrating as the initial mapping of results-oriented PSS suggested a 
broader scope for environmental improvements could be achieved across the various stages of the 'home lifecycle': a more holistic view of home-ownership across all of its phases. This reflects a particular issue of designing around unknown, and perhaps ill-defined, concepts such as PSS in practice. For example, the redesign of a product can present radical departures from the familiar form of the product, but the concept of 'a product artifact' in and of its self, remains unchallenged. Take the design of a hybrid car; it comprises many radically innovative features, both in the technology and the user interface design, but in essence it still remains a car - a material artifact. However if the design focus shifts to the larger scale issue of effective urban mobility, this initiates questions concerning the appropriateness of individual transportation as an urban system response to mobility and opens up very different potential design outcomes. Add into this mix the question of the need for individual ownership of material artifacts or systems of service utility, and the potential for more far-reaching design concepts increases again through a set of evolving relationships between existing actors and the establishment of new relationships over time.

The challenges of how to translate PSS theory into what to design was apparent early in this design process and as the process evolved, the expectations and drivers of the existing modes of doing from the house-builder, steered the overall direction of the result focused PSS concepts (e.g. clean clothes, tidy garden) developed for user feedback. The project mandate of result oriented service provision to prevent waste and therefore reduce associated environmental impact in housing developments was managed alongside the realities of practice: the system of delivery, the demands of the supply side management and the expectations of users. In this regard the design process was typical; it was iterative and responsive to 'client' demands where the client was the house builder. Reflecting on the process it is unfortunate that the householders were not involved in the development of the detail of the PSS offer in stage two of the process. This would have provided different perspectives on service opportunities and perhaps generated new information that could have encouraged the house builder and their facilities management service provider to explore a wider range of PSS outputs.

In designing effective PSS outcomes that introduce new types of lifestyle expectations and behaviour (for that is the opportunity PSS presents), a much deeper and thoughtful approach to local contexts and needs is required and opportunities for participatory design explored. To ask people to live differently for environmental and social benefits requires a design process sensitive to change and responsive to the challenges of transition. The process described here integrates some elements of a context sensitive, participatory approach such as the mapping of multiple external factors, contexts and boundaries and the generation of evaluative design criteria from the different actors, that begin to demonstrate a greater awareness of the critical interconnections between products, services and systems in delivering new types of more environmentally benign outcomes.

It is from a process routed in practical experiment and judgment that useful, yet tentative criteria can emerge that help to anticipate the potential of result-oriented PSS and their associated performances. An engagement with many actors throughout this process drew out practical wisdoms concerning expectations of delivery, supply and infrastructure; this specifically occurred in the early mapping exercises and through the semi-structured interviews with the house-builder, the facilities management business and with new householders in generating a series of design criteria as part of the multi-criteria evaluation methodology (AHP). Where the multi-criteria method perhaps too narrowly restricted the actors' response space was in its use as a mechanism to 'close down' design thinking opportunities at the earlier stages of the design process and prevent the generation of other applicable result oriented PSS solutions. The very nature of an AHP approach requires upfront analysis of the area to be tested using the actor interview data alongside secondary sources. This analysis feeds the structure of the content for the AHP framework in terms of the evaluation design criteria and the small 'response space' for respondents to comment on the design concepts (limited criteria are presented). The data generated from such an 
exercise provides useful insights into the choices people make and their priorities and tradeoffs and is a particularly useful methodology when there is a well-defined thing to explore and test. However, in the case of this project with its emerging knowledge of result oriented PSS in a 'real-world' domestic build context, the experiment was an exploration of a range of uncertainties and undefined relationships between people, product and systems of trade, and perhaps the more rigid AHP evaluation dis-enabled the exploration of peoples' preferences for alternative deliverables at an early stage of the design process.

In conclusion this project was commercially led and was context and sector specific in its focus; it was very much a practical foray into developing concept PSS with commercial interests driving decision-making. Commercial actors perceived PSS were worth exploring in terms of whether they could generate profit and create additional vale for households. Equally, the funder was keen to explore opportunities for waste reduction through PSS by reducing product ownership in the domestic household. The house builder's imperative to close sales reflects sector priorities and preferences and perhaps best highlights why more adventurous PSS concepts like home lifecycle and relationships that foster longevity currently do not fit easily with existing business-as-usual practices (Tukker and Tischner, 2006). The resultant PSS may be considered predictable but this in itself is a key point. To produce different models of outcome within the existing constraints of the marketplace is a very difficult task; it requires very different thinking and as such, this project reflects the barriers to changing perceptions. Fitting different types of PSS to current commercial constraints was not deemed viable in this context. This is a key outcome from the project and raises the important question of whether a greater emphasis on the design imperative in PSS is critical for creating new types of value. How can design practice create more meaningful outcomes that meet peoples' needs, create new values of wealth and wellbeing and reduce environmental impacts across whole life? How do we practically experiment with PSS? How do designers journey beyond the constraints of current rules, structures and expectations to grow this new knowledge, grounded in practice? PSS are fuzzy, unbounded concepts. As such they present an opportunity to inspire a new generation of solutions in the way we utilize resources and the systems that support those resources and products. The evolution of, and definition of PSS will result from the practical experimentation of these ideas in various contexts. PSS are made in the early phases of diffusion and thus it is through these places and practices where new knowledge on designing PSS will begin to emerge.

\section{Acknowledgements}

The findings reported in this paper were drawn from a project funded by Department for Environment, Food and Rural Affairs (Defra). The views expressed in this paper are those of the authors and do not necessarily reflect Defra policy.

\section{WORDS 6729 (excluding Abstract, Acknowledgements \& References)}

\section{References}

Baines, T., H. Lightfoot, S. Evans, A. Neeley, R. Greenough, J. Peppard, R. Roy, E. Shehab, A. Braganza, A. Tiwari, J. Alcock, J. Angus, M. Bastl, A. Cousens, P. Irving, M. Johnson, J. Kingston, H. Lockett, V. Martinez, P. Michele, D. Tranfield, I. Walton and H. Wilson. (2007) 'State of the art in product service systems', Journal of Engineering Manufacture 221, 15431552.

Bartolomeo, M., D. dal Maso, P. de Jong, P. Eder, P. Groenwegen, P. Hopkinson, P. James, L. Nijhuis, M. Orringe, G. Scholl, A. Slob and O. Zaring. (2003), Eco-efficient producer services - what are they, how do they benefit customers and the environment and how likely are they to develop and be extensively utilised? Journal of Cleaner Production 11, 829-837. 
Behrendt, S., Jasch, C., Kortman, J., Hrauda, G., Firzner, R. and Velte, D. (2003) Ecoservice Development: Reinventing Supply and Demand in the European Union, Sheffield, Greenleaf publishing.

Brezet, J., A. Bijma, J. Ehrenfeld and Silvester, S. (2001), The design of eco-efficient services. Delft, Report by TU Delft for the Dutch Ministry of the Environment.

Cook, M.B., Bhamra, T. A., Lemon, M. (2006), 'The transfer and application of Product Service Systems: from academia to UK manufacturing firms', Journal of Cleaner Production, $14,1455-1465$

Dorst, K., and Cross, N., (2001), 'Creativity in the design process: Co-evolution of problemsolution', Design Studies , 22, 425-437.

Gershuny, J. and Miles, I. (1983), The new service economy: the transformation of employment in industrial societies. London: Pinter.

Goedkoop, M., Halen C., Riele H. and Rommens P., (1999), Product Service Systems, Ecological and Economic Basics. Netherlands, PricewaterhouseCoopers, Storrm, Pré Consultants for Ministry of Economic Affairs.

Gottberg, A., Longhurst, P., Cook, M. (2010), 'Exploring the Potential of Product Service Systems to Achieve Household Waste Prevention in the UK', Waste Management and Research, 28, 228-235.

Heiskanen, E. \& Jalas, M. (2003) 'Can services lead to radical eco-efficiency improvements? - A review of the debate and evidence', Corporate Social Responsibility and Environmental Management, 10, 186-198.

Hockerts, K. (1999). Innovation of eco-efficient service: increasing the efficiency of products and services, in Greener marketing: a global perspective on greener marketing practice, M. Charter and M. J. Polonsky (eds), Sheffield, Greenleaf Publishing.

Howells, J. (2002), Innovation, consumption and services: encapsulation and the combinational role of services, paper presented at the $12^{\text {th }}$ International RESER conference, 26-27 September, Manchester.

Meijkamp R. (2000), Changing consumer behaviour through 'eco-efficient services: an empirical study on car sharing in the Netherlands. Delft: Delft University of Technology.

Mont, O. and Lindhqvist, T. (2003) The Role of Public Policy in Advancement of Product Service Systems, Journal of Cleaner Production 11, 905-914

Mont, O. (2004), 'Institutionalisation of sustainable consumption patterns based on shared use', Ecological Economics, 50, 135-153.

Mont, O. and Tukker, A. (2006) 'Product-service systems: reviewing achievements and refining the research agenda', Journal of Cleaner Production, 14, 1451-1454.

Mont, O. and Emtairah, T. (2008), 'Systemic changes and sustainable consumption and production', In System innovation for sustainability: perspectives on radical changes to sustainable production and consumption v1., ed. A. Tukker, M. Charter and C. Vezzoli. Sheffield, Greenleaf Publishing.

Pahl, G., Beitz, W., Feldhusen, J., and Grote, K.-H. (2007), Engineering design: A systematic approach, (3rd ed.), Springer-Verlag,. 
Roy, R. (2000), 'Sustainable Product-Service Systems', Futures, 32, 289-299.

Saaty T.L. (1980), The Analytic Hierarchy Process. Planning, Priority Setting, Resource Allocation, New York, McGraw- Hill

Schimidt-Bleek, F. (2000), 'Factor 10 Manifesto'. Carnoules: Factor 10 Institute, [online] http://www.factor10-institute. org/publications. html, (Accessed 17th April 2010)

Sorrell S. (2007), 'The economics of energy service contracts', Energy Policy 35: 507-521.

Taha, H, A., (2003) Operations Research: an introduction, New Jersey, Prentice Hall International Edition

Tischner, U., Verkuiji M. and Tukker, A. (2002), Product service systems: best practice document: SusProNet, Professional Engineering Publishing Limited.

Tukker, A. and Tischner, U. (2006) 'Product-services as a research field: part, present and future. Reflections from a decade of research, A note from the field', Journal of Cleaner Production, 14, 1552-1556.

van den Hoed, R. (1997), 'Shift from products to services: an example of washing services', Proceedings Towards Sustainable Product Design 2nd international Conference, London, July.

Weizsacker E, Lovins A, Lovins H. (1997), Factor Four, Doubling Wealth Halving Resource Use, London, Earthscan.

Williams A., (2007), 'Product service systems in the automobile industry: contribution to system innovation?', Journal of Cleaner Production ,15, 1093-1103.

White, A. L., Stoughton, M., and Feng, L. (1999), Servicizing: the quiet transition to extended product responsibility, Boston, Tellus Institute.

Zaring, O., Bartolomeo, M., Eder, P., Hopkinson, P., Groenwegen, P., James, P., de Jong, P., Nijhuis, L., Scholl, G., Slob, A., Orringe, M., (2001), Creating eco-efficient producer services, Sweden, Gothenburg Research Institute.

\section{Figure captions}

Figure 1 A PSS design process

Figure 2 The Home Lifecycle

Figure 3 Home Improvement and Laundry PSS 